\title{
ANALYSIS AND RESEARCH ON THE DIVERSITY OF MICROBIAL COMMUNITY STRUCTURE IN URBAN RIVER SEDIMENT
}

\author{
TU, B. H. - OU, Y.T. - ZHAO, Y.* - QIN, W. - XiAO, X. - ZhANG, S.* - LIU, Y. \\ School of Environmental and Safety Engineering, Changzhou University, Changzhou, Jiangsu \\ 213164, China \\ Changzhou City New Materials Technology Co. LTD, Changzhou, Jiangsu 213000, China \\ *Corresponding authors \\ e-mail/phone: zhaoyuan@cczu.edu.cn/+86-159-6123-8081 (ZHAO, Y.); \\ zhangsheng@cczu.edu.cn/+86-139-5122-6900 (ZHANG, S.) \\ (Received $9^{\text {th }}$ Apr 2019; accepted $19^{\text {th }}$ Jun 2019)
}

\begin{abstract}
In this study, sediment was sampled from the North River in Changzhou at five different loca-tions at the same time. Microbial DNA was extracted from the obtained samples, and the extracted DNA purity was compared by two different methods. After DNA amplification by $16 \mathrm{~S}$ rRNA PCR, microspectrophotometry and agarose gel electrophoresis, the modified gradient gel electrophoresis (DGGE) was performed. The DGGE map was analyzed using Quantity one software of bio-rad to study the community diversity. The similarity matrix showed that the samples of different locations and time had high similarity, with the highest similarity reaching $82 \%$. The proportion of similarity over $60 \%$ is extremely high, which indicates that the microbial population in North River is abundant, but the microbial community structure changes little in space.
\end{abstract}

Keywords: sediment, spatial variation, PCR amplifiction, DGGE, microbial diversity

\section{Introduction}

Urban rivers are part of natural river basins, playing an irreplaceable role in the process of urban ecological construction, namely, they have the functions of material circulation and ecological protection, weakening the urban heat island effect and regulating local climate (Yan and Wang, 1999). Due to the rapid development of human urbanization, the natural ecosystem of urban rivers is overused, damaged and difficult to recover. Resulting in the loss of self-purification capacity and the rapid deterioration of the environment, which seriously affects the urban ecological environment and the health of urban residents (Sun, 2015). With the continuous improvement of living standards, people are constantly strengthening their environmental awareness, and the quality of living environment is also constantly improving, which leads to the prominent problem of urban river pollution, and its governance is of great urgency. At present, physical, chemical and biological methods have been used to restore and manage damaged river ecosystems ( $\mathrm{Hu}$ et al., 2005). Compared to physical and chemical methods, biological methods do not cause secondary pollution in the treatment, and the cost of investment and maintenance is low ( $\mathrm{Gu}$ et al., 2013). In addition, the study on the microflora of urban river environments in China has been available in the 1980s. For example, since 1986, Zhao et al. used traditional culture methods to study the correlation between organic matter and water temperature in water and microbial quantity and population distribution (Zhao et al., 1986). Therefore, it is of great significance to study the community structure and functional diversity of microorganisms in known environments. Combined with the existing methods of 
environmental microorganism community analysis, there are traditional culture and separation methods (Amann et al., 1995). Community level physiology fingerprint methods (CLPP) (Victorio et al., 1996; Ibekwe and Kennedy, 1998), biological marker methods (Bai, 1997) and modern molecular biology methods (Torsvik et al., 1990; Hill et al., 2002; Handelsman, 2004; Tunlid, 2007). Since 1985, Pace et al. (1997) used the accounting sequencing method to study microbial evolution, molecular biology technology has been gradually introduced into biodiversity research. In 1993, Muyzer et al. (1993) first introduced the denatured gradient gel electrophoresis DGGE technology into the study of microbial ecology (Zhang et al., 2009; Yu et al., 2010). Since then, DGGE technology has been applied and developed in environmental microorganism research. Therefore, in this study, taking the North River in Changzhou city as an example, the microbial community structure of the urban river is analyzed with the PCR-DGGE (Röttgers, 2007) technology. Through analyzing the target environment of microbial community structure and population diversity, we supplied a reference for optimizing the community structure, regulating functions of community, and discovering new important microbial groups.

\section{Materials and methods}

\section{Experimental materials}

\section{River sediment}

The river bottom sediment samples were collected in the North River, and the locations of the river bottom sediment samples were Jingu Manor, Boai Bridge, Chunting Bridge, Zhiyuan Bridge and Yuanfeng Bridge (as shown in Fig. 1). In order to facilitate the experimental record, the samples of the above five locations were recorded as no.1,2,3,4 and 5, respectively. As there are residential communities near the river section, part of the sewage will be directly discharged into the river section. But in recent years, beishi river has improved its water quality by adding aeration devices and installing biological floating islands. The samples of river surface sediment $(0 \sim 20 \mathrm{~cm})$ were collected from January to December 2017 and all of them were gathered using sterile bags. At $4{ }^{\circ} \mathrm{C}$ under the condition of back to the laboratory immediately, save under the condition of $-80^{\circ} \mathrm{C}$, and completed within a week of sediment microbial total DNA extraction.

\section{Preparation of buffer solution}

(1) 50×TAE preparation: Tris $242 \mathrm{~g}$, Na2EDTA $2 \mathrm{H} 2 \mathrm{O} 37.2 \mathrm{~g}$, and then $800 \mathrm{ml}$ of deionized water was added, which was fully stirred to dissolve. Add $57.1 \mathrm{ml}$ acetic acid and mix well. Finally, add the deionized water to $1 \mathrm{~L}$ for storage at room temperature. $(50 \times \mathrm{TAE}$ is the storage fluid. Dilute 50 times to get $1 \times \mathrm{TAE}$ solution)

(2) $5 \times$ Loading buffer preparation: $10 \mathrm{mM}$ tris-hcl, $5 \mathrm{mM}$ EDTA, $\mathrm{pH} \mathrm{7.6,0.03 \%}$ bromophenol blue, $0.03 \%$ xylene blue, $30 \%$ glycerin.

\section{Experimental methods}

\section{Determination of physical and chemical properties of North River sediment}

Dissolved oxygen and water temperature should be measured at the sampling site, and immediately measured by the Shanghai Jingke jpbj-608 portable dissolved oxygen meter. $\mathrm{pH}$, ammonia nitrogen, total nitrogen, total phosphorus, chemical oxygen demand, nitrate nitrogen and chlorophyll a were measured in the laboratory. The determination of 
chemical oxygen demand, ammonia nitrogen, total nitrogen and total phosphorus was carried out by the 6b-2000 multi-parameter water quality meter of Jiangsu Shengaohua Environmental Protection Technology Co. LTD. The determination of $\mathrm{pH}$ was carried out by using a multiple parameter analyzer. Chlorophyll a was determined by spectrophotometer (Röttgers, 2007). The determination of nitrate nitrogen was performed by UV spectrophotometry (Zhu et al., 2011), that is, the absorption area of nitrate ion at the wavelength of $220 \mathrm{~nm}$ was used for quantitative determination of nitrate nitrogen.

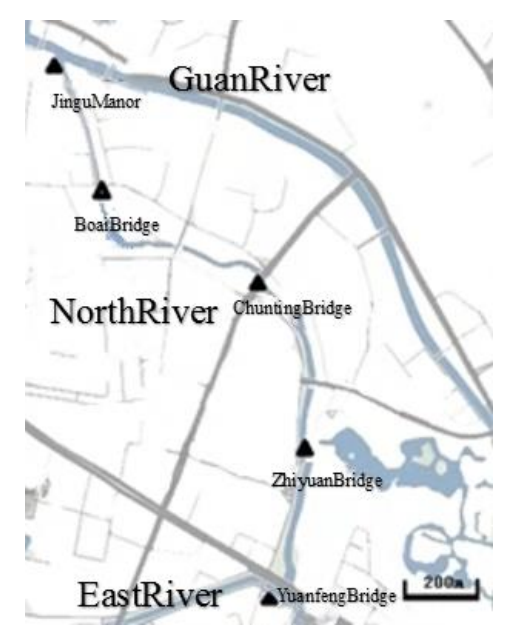

Figure 1. North River sampling section distribution schematic diagram

\section{Total DNA extraction of river sediment microorganisms}

The $1 \mathrm{~g}$ bottom sediment samples were respectively weighed and used in combination with humic acid by bioengineering (Shanghai) company, and 0.2-0.5 g bottom sediment samples were extracted from the bottom sediment samples by using Omega biotek soil DNA small-lift kit. The operation steps were performed according to the instructions, and the extraction effect was compared.

\section{Inspection of DNA concentration and purity}

This study used an ultra-micro spectrophotometer to determine the concentration of DNA. $2 \mu \mathrm{L}$ of DEPC tretd water was taken as a blank sample and $2 \mu \mathrm{L}$ of the total DNA solution of the sediment sample, and each was dropped in the measurement area of the micro spectrophotometer, and the relevant data was recorded by an analysis software. If the ratio of A260/A280 is around 1.8, it means that higher DNA concentration can be used for subsequent PCR and cloning experiments. If A260/A280>2.0, it means that the RNA interference is large and the DNA needs to be re-expressed (Hoefel et al., 2005).

\section{PCR amplification}

In the present study, the amplified DNA fragment was subjected to the V3 region of the bacterial 16S rRNA sequence, and the primers were $357 \mathrm{f}$ and $518 \mathrm{r}$ ( $\mathrm{Li}$ et al., 2013), and the length was about $194 \mathrm{bp}$. Further, a "GC" splint having a base number of $40 \mathrm{bp}$ was added to the 5 ' portion of the primer $357 \mathrm{f}$. which is “GC” splint: 5'-CGCCCGCCGCGCCCCGCGCCCGGCCCGCCGCCCCCGCCCC -3' 


\section{7f: 5'-CCTACGGGAGGCAGCAG-3'}

\section{8r: 5'-ATTACCGCGGCTGCTGG-3'}

Reaction system: (1) PCR reaction system is $25 \mu \mathrm{L}$, the specific reagent amount: $2 \times$ Taq Master mix $12.5 \mu \mathrm{L}$; upstream primer $2 \mu \mathrm{L}$; downstream primer $2 \mu \mathrm{L}$; DNA template $1.25 \mu \mathrm{L}$; $\mathrm{DDH}_{2} \mathrm{O} 7.25 \mu \mathrm{L}$; (2) PCR reaction system is $50 \mu \mathrm{L}$, the specific reagent amount: $2 \times$ Taq Master mix $25 \mu \mathrm{L}$; upstream primer $1 \mu \mathrm{L}$; downstream primer $1 \mu \mathrm{L}$. DNA template $2 \mu \mathrm{L}$; $\mathrm{DDH}_{2} \mathrm{O} 21 \mu \mathrm{L}$.

Amplification procedure: pre-denaturation at $94{ }^{\circ} \mathrm{C}$ for $5 \mathrm{~min}$, then 25 cycles, each cycle includes denaturation at $94{ }^{\circ} \mathrm{C}$ for $30 \mathrm{~s}$, annealing at $61-56{ }^{\circ} \mathrm{C}$ for $30 \mathrm{~s}$, extension at $72{ }^{\circ} \mathrm{C}$ for $1 \mathrm{~min}$, and end of the cycle at $72{ }^{\circ} \mathrm{C}$ for a final extension of $7 \mathrm{~min}$. Hold $4{ }^{\circ} \mathrm{C}$.

\section{DNA agarose gel electrophoresis experiment (qualitative analysis)}

The extracted total DNA was qualitatively analyzed by agarose gel electrophoresis. $0.25 \mathrm{~g}$ of agarose was added to $1 \times \mathrm{TAE}$ buffer, and a $1 \%$ agarose gel was subjected to electrophoresis, and the results were observed after photographing under an ultraviolet lamp.

\section{DNA denaturing gradient gel electrophoresis (DGGE) experiment}

Solidifying the gel in $1 \times \mathrm{TAE}$ buffer, each sample well of a sample of about $15 \mu \mathrm{L}$, using horizontal electrophoresis, a gradient of denaturant is allowed to range from $40 \%$ to $55 \%$, the voltage $75 \mathrm{~V}$, run time $14 \mathrm{~h}$, electrophoresis was carried out at a temperature of $60^{\circ} \mathrm{C}$. After the electrophoresis of the DGGE gel was completed, it was stained with EB (ethidium bromide). After staining, images were taken using a gel imaging system and images were quantified using BIO-RAD's Quantity One software (Li et al., 2013). And by digitally converting DGGE maps, the species diversity was analyzed. In this study, Shannon-Wiener index $\left(H^{\prime}\right)$ (Xu et al., 2011), Simpson index $(D)$ (Sun and Liu, 2004) and Pielou index ( $J$ ) (Liu et al., 2013) were used to characterize the species diversity of their communities, which calculated as follows:

$$
\begin{gathered}
H^{\prime}=-\sum_{i=1}^{n} p_{i} \ln p_{i} \\
D=\sum_{i=1}^{n} p_{i}^{2} \\
J=-\sum_{i=1}^{n}\left(p_{i} \ln p_{i}\right) / \ln S=H^{\prime} / \ln S
\end{gathered}
$$

where $n$ indicates the number of bands detected in each sample, and $S$ indicates the sum of the different bands detected by DGGE, indicating the gray level of each band in the sample as a percentage of the total gray scale of the sample. 


\section{Results and discussion}

\section{Analysis of the pollution status of the sediments in The North River}

\section{Analysis of pollution status of nitrogen element in sediments of The North River}

\section{(1) Ammonia nitrogen}

As shown in Figure 2, the ammonia nitrogen was varied in the range of 0.2 to $0.7 \mathrm{mg} / \mathrm{g}$, and the average value was $0.45 \mathrm{mg} / \mathrm{g}$. In terms of river flow, the content of ammonia nitrogen in each section is Boai Bridge $>$ Chunting Bridge $>$ Jingu Manor $>$ Yuanfeng Bridge $>$ Zhiyuan Bridge, that is, upstream ammonia nitrogen content > middlestream > inlet > export > downstream; in terms of time, ammonia nitrogen content The monthly value has changed slightly but the change has not changed much. It can be seen that the ammonia nitrogen value of river sediment is not affected by seasonal temperature changes (Qin et al., 2014).

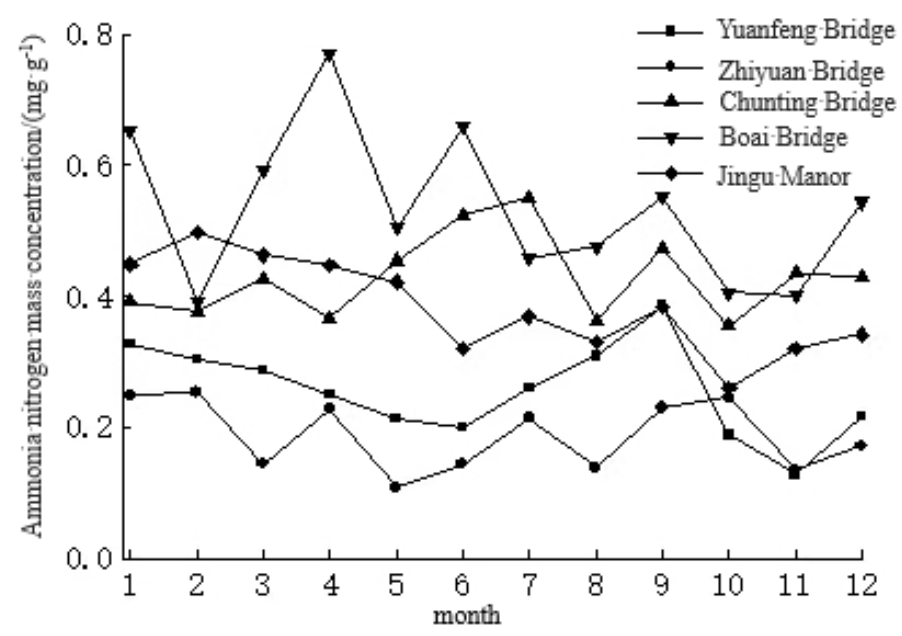

Figure 2. The change trend of ammonia-nitrogen

\section{(2) Nitrate nitrogen}

As shown in Figure 3, the nitrate nitrogen ranged from 0 to $0.06 \mathrm{mg} / \mathrm{g}$ with an average of $0.04 \mathrm{mg} / \mathrm{g}$. In terms of river flow, the sediment content of each section is Jinyuan Manor > Boai Bridge > Chunting Bridge > Zheyuan Bridge > Yuanfeng Bridge, which is the inlet nitrate nitrogen content $>$ upstream $>$ middlestream $>$ downstream > export; in terms of time, sediment The content of nitrate nitrogen did not change much, but the Boai Bridge increased slightly in the spring, and the Qiating Bridge increased in summer. The reason for this phenomenon is as follows: (1) The relative error of the measured value is too large due to the low nitrate content of the measured nitrate; (2) The resin adsorption treatment of the sediment sample is not carried out in this experiment, resulting in a high value measured at $220 \mathrm{~nm}$, which causes it to be subjected to Interference with organic matter.

\section{(3) Total nitrogen}

As shown in Figure 4, the variation range of $\mathrm{TN}$ is between 1 and $3.5 \mathrm{mg} / \mathrm{g}$, and the average value is $2.05 \mathrm{mg} / \mathrm{g}$. In terms of river flow, the total nitrogen content of each 
section of the sediment is Boai Bridge $>$ Chunting Bridge $>$ Jingu Manor $>$ Yuanfeng Bridge $>$ Zhiyuan Bridge, its variation law is consistent with the change of ammonia nitrogen content in all sections, that is, upstream ammonia nitrogen content $>$ midstream $>$ inlet $>$ export $>$ downstream; in terms of time, the total nitrogen content of sediment has little fluctuation in each month. It can be seen that the total nitrogen content of the sediment is not affected by seasonal temperature changes.

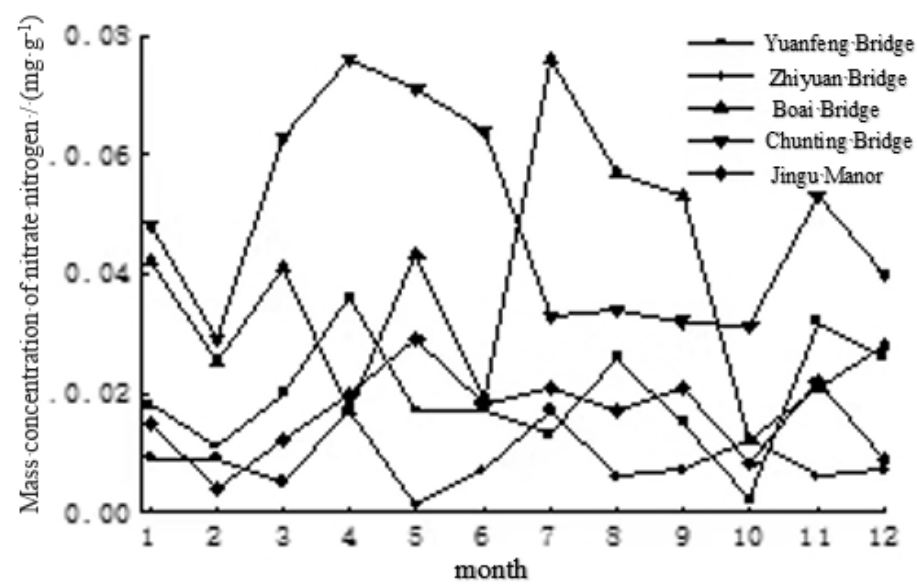

Figure 3. The change trend of nitrate nitrogen

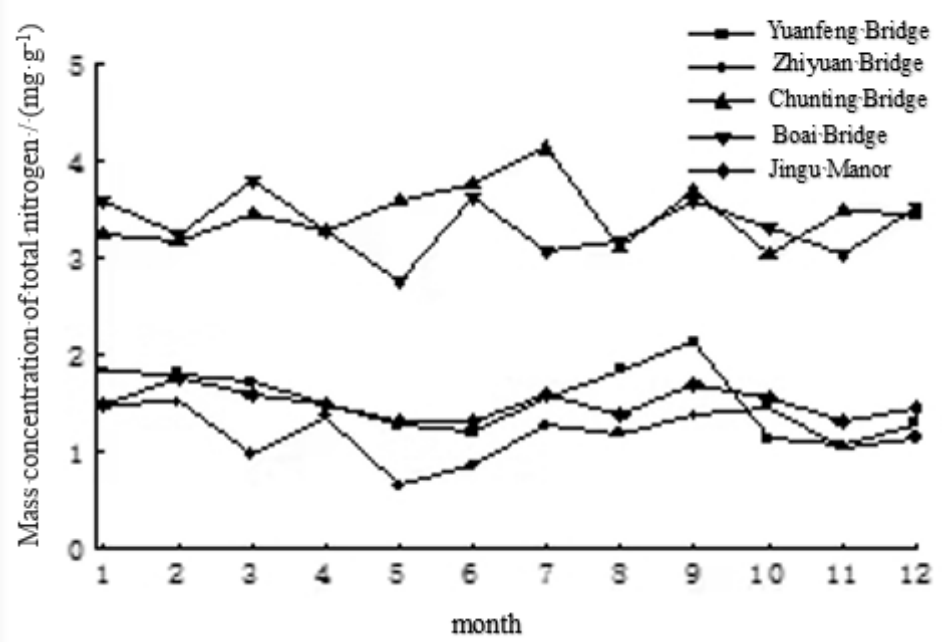

Figure 4. The change trend of TN

As Chunting Bridge and Boai Bridge are both in densely populated areas, the river is polluted more seriously, and the nutrient element nitrogen value is higher. In addition, Yuanfeng Bridge and Jinyin Manor are connected to Dongshi River and Guanhe River respectively, so the nutrient nitrogen element the content is affected by Donghe River and Guanhe River; and Zhiyuan Bridge is located in Hongmei Park of Changzhou City. The surrounding trees have a positive impact on the environment, which makes the nitrogen content of nutrient elements low. It can be seen that the nutrient nitrogen 
content of the river bottom mud in Beishi is affected by human activities and the surrounding environment.

\section{Analysis of pollution status of phosphorus in the sediment of The North River}

As shown in Figure 5, the range of TP was 1 to $2 \mu \mathrm{g} / \mathrm{g}$, and the average value was $1.35 \mu \mathrm{g} / \mathrm{g}$. In terms of river flow, the content of TP in each section of the sediment is Boai Bridge $>$ Chunting Bridge $>$ Yuanfeng Bridge $>$ Jingu Manor $>$ Zhiyuan Bridge, which is the upstream TP content > middlestream > export > inlet > downstream; in terms of time, TP content in each month There has been a slight change, but the change is not large. It can be seen that the phosphorus content of the nutrient element in the sediment is not affected by seasonal temperature changes (Zeng et al., 2009).

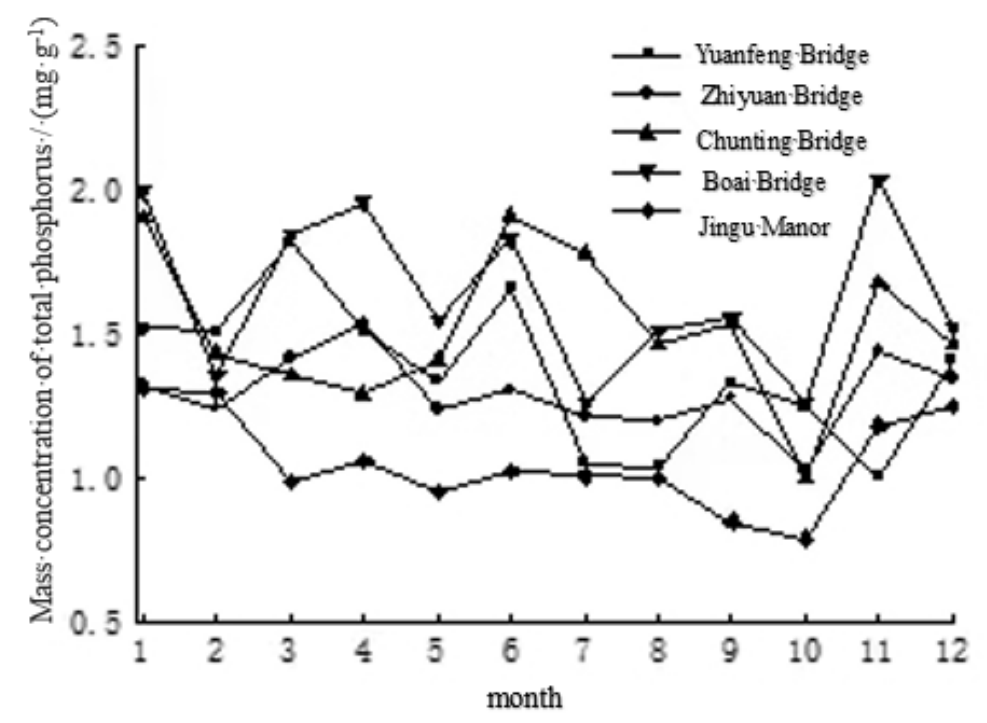

Figure 5. The change trend of TP

From the above analysis of pollution conditions, it can be seen that the changes in the contents of $\mathrm{N}$ and $\mathrm{P}$ in the river bottom mud of Changzhou City are consistent. In terms of time, the content of $\mathrm{N}$ and $\mathrm{P}$ did not change much in each month, and was basically not affected by seasonal temperature. In terms of river flow, the content of upstream $\mathrm{N}$ and $\mathrm{P}$ was greater than that of midstream and greater than downstream. The nitrogen and phosphorus in the sediment are mainly derived from the discharge of domestic sewage from nearby residents, landfill leachate, and discharge of restaurant wastewater from nearby restaurants.

The $\mathrm{pH}$ value of the sediment varies from 5 to 6.7 , which is weakly acidic. The average value of TN is $2.05 \mathrm{mg} / \mathrm{g}$, the average value of TP is $2.05 \mathrm{mg} / \mathrm{g}$, the average value of ammonia nitrogen is $0.45 \mathrm{mg} / \mathrm{g}$, and the average value of nitrate nitrogen is $0.04 \mathrm{mg} / \mathrm{g}$. The river bottom mud has been polluted by $\mathrm{N}$ and $\mathrm{P}, \mathrm{N}$ and $\mathrm{P}$ belong to medium pollution level, and the degree of TP pollution is slightly higher than TN. The benthic community has suffered some damage, but it is still within the acceptable range.

The $\mathrm{N}$ element in the sediment as a double indicator mainly reflects the pollution degree and nutritional status of the Beishi River, while the $\mathrm{P}$ element is one of the important indicators reflecting the pollution degree of the Beihe River. For microbial 
community structure analysis, $\mathrm{N}$ and $\mathrm{P}$ have a certain correlation with microbial community diversity, but the effect of $\mathrm{N}$ element on microbial community is not significant, but $\mathrm{P}$ element has great influence on microbial community (Peng et al., 2009).

\section{Extraction of microbial total DNA from sediment samples}

The total DNA of the extracted sediment sample, if extracted by the soil DNA extraction kit, is invisible after drying, and the solution after dissolution with TE Buffer is light brown; if using the soil total DNA kit and humic acid It can be clearly seen after drying, and the white particles are clearly visible, and the brown matter is formed on the edge, and the solution dissolved by TE Buffer is colorless and transparent, or light brown.

The DNA extracted by the two methods was subjected to agarose gel electrophoresis. The map of the extract of the soil DNA extract kit was shown in Figure 6. The extract of the total DNA kit and the humic acid was as shown in Figure 7.

By observing the agarose gel electrophoresis patterns of the two methods, the soil extract kit has a small amount of DNA and more impurities. The total DNA kit combined with humic acid extracts more DNA and less impurities. In order to save costs and improve the accuracy of the experiment, only the extract obtained by the combination of the total DNA kit and the humic acid was used as the experimental material in the subsequent experiments.

\section{Test of DNA concentration and purity}

It can be seen from Tables 1 and 2 that the OD260/OD280 values of the DNA extract of the soil extract kit are all greater than 2.0, indicating that the RNA and impurities contained therein are large, which does not meet the requirements of subsequent experiments. The total DNA purity of the sediment samples extracted from the total DNA kit combined with humic acid is higher and the content is higher. The OD260/OD280 values are less than 2.0 and greater than 1.6, which means that the extracted total DNA can be used as Subsequent PCR amplification experiments.

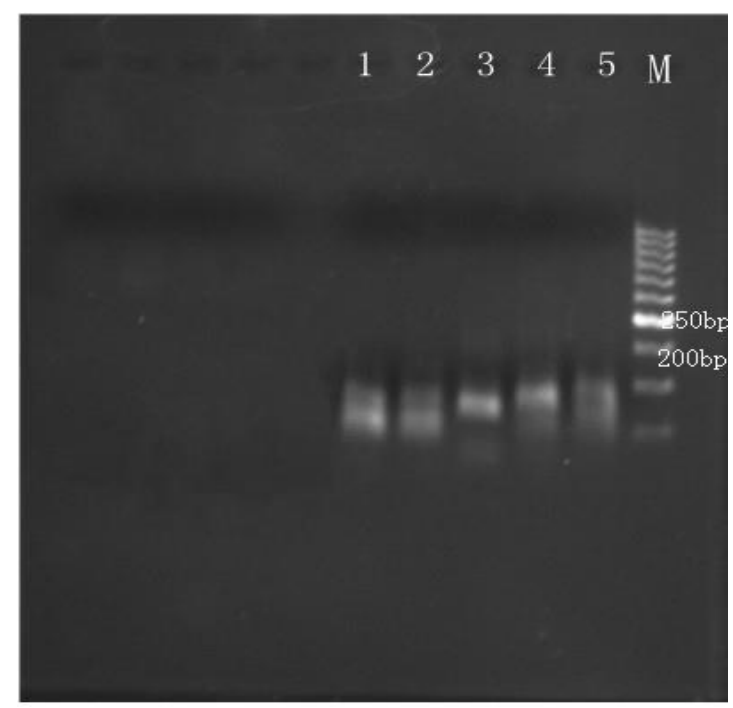

Figure 6. Electrophoresis pattern of extracts of soil DNA kit by agarose gel 


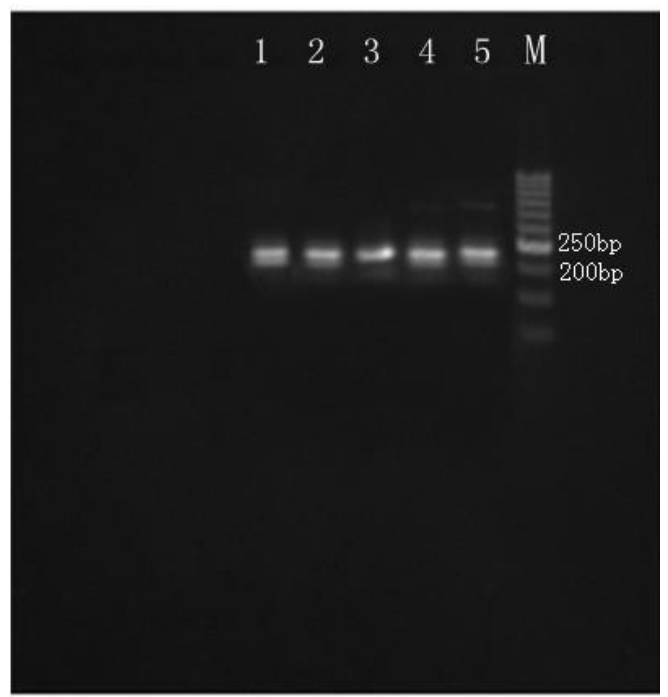

Figure 7. Electrophoresis pattern of extracts of soil total DNA kits and humus acids combined by agarose gel

Table 1. Extraction of DNA concentration and purity by soil DNA kit

\begin{tabular}{c|c|c|c|c}
\hline DNA sample & $\mathbf{1}$ & $\mathbf{2}$ & $\mathbf{3}$ & $\mathbf{4 5}$ \\
\hline Sample size/(g) & 0.3 & 0.3 & 0.3 & 0.30 .3 \\
OD260/OD280 & 1.64 & 1.72 & 1.57 & 1.621 .60 \\
OD260/OD230 & 1.12 & 1.10 & 1.13 & 1.121 .11 \\
DNA yield/(ng/ $\mu \mathrm{L})$ & 57.92 & 62.97 & 57.32 & 58.7360 .02 \\
\hline
\end{tabular}

Table 2. Extraction of DNA concentration and purity by soil total DNA kits and humus acids combined

\begin{tabular}{c|c|c|c|c}
\hline DNA sample & 1 & 2 & 3 & 45 \\
\hline Sample size/(g) & 0.3 & 0.3 & 0.3 & 0.30 .3 \\
OD260/OD280 & 2.35 & 2.08 & 2.29 & 2.282 .25 \\
OD260/OD230 & 1.07 & 1.13 & 1.13 & 1.401 .28 \\
DNA yield/(ng/ $\mu \mathrm{L})$ & 27.62 & 29.08 & 30.22 & 28.0029 .53 \\
\hline
\end{tabular}

DNA samples $1,2,3,4$, and 5 in Tables 1 and 2 are the DNA extracts of the Beihe River sediment samples from five different locations of Jingu Manor, Boyai Bridge, Qiting Bridge, Zhiyuan Bridge and Yuanfeng Bridge

\section{Agarose gel electrophoresis test of PCR products (qualitative analysis)}

After extracting the total DNA of the microbes in the sediment, the agarose gel electrophoresis experiment was carried out, and the DNA content was analyzed qualitatively. Its ultraviolet transmission spectrum is shown in Figure 8. This is a PCR amplified DNA agarose gel electrophoresis. Among them, $\mathrm{M}$ was the marker (normalruntm100bp-iv DNA Ladder), and 1 to 5 were the electrophoresis bands obtained after the amplification of microbial total DNA at five different sampling points, namely Jingu Manor, Boai Bridge, Chunting Bridge, Zhiyuan Bridge and 
Yuanfeng Bridge. The figure shows that the amplified target band is bright and clear with good specificity, and the amplified product is about 200bp to 250bp.

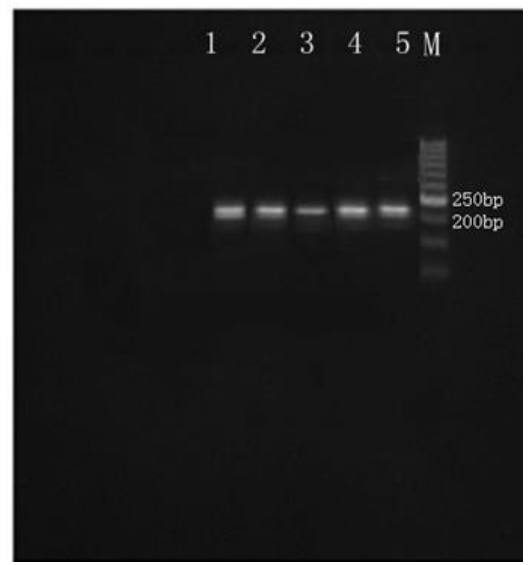

Figure 8. Electrophoresis pattern of PCR products by agarose gel

\section{Denaturing gradient gel electrophoresis (DGGE) experiment of DNA}

The DGGE spectra of the sediment samples from five different sections of The North Riiver (Jingu Manor, Boai Bridge, Chunting Bridge, Zhiyuan Bridge and Yuanfeng Bridge) are shown in Figure 9. The DGGE map indicates that the strains in the sediments of The North River have a high degree of richness. In addition, the DGGE band spectrum has some differences in the number and position of the bands and the brightness of the bands, indicating that the microbial community composition of different samples is also different.

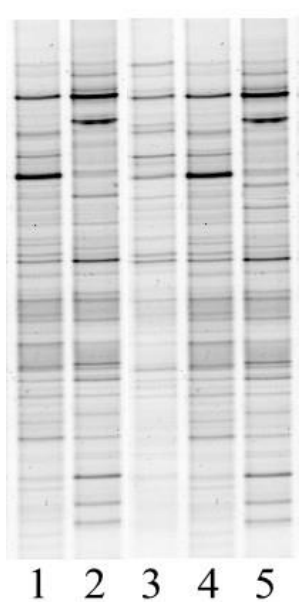

Figure 9. DGGE map of five samples of North River mud

BIO-RAD's Quantity One software analyzes DGGE maps, which allow manual and automated quantification of lanes and bands and then output results based on analysis needs. The chart below will be the lane/strip recognition map (Fig. 10) and the similarity matrix (Fig. 11) analyzed using Quantity One software. 


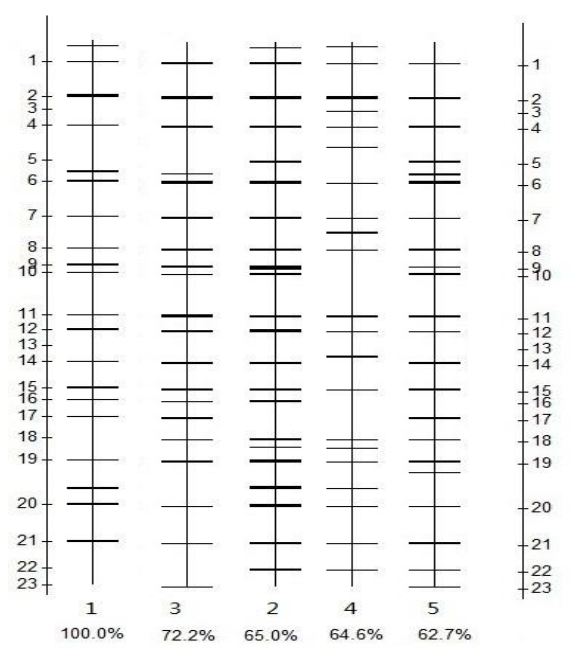

Figure 10. Lane/strip identification maps of five samples of North River

The sediment samples of the five different sections of the North River are shown in Figure 10. The standard for the lane identification map is C1. Identify the thickness of the lines in the figure, the thick strips indicate that the corresponding density on the DGGE glue is large, and the thin strips indicate that the density is relatively small; in the figure, 23 strips appearing more, 1 and 2 No. 4, No. 6, No. 6, No. 7, No. 8, No. 11, No. 15, No. 15, No. 20 and No. 21 appear in each sample; No. 9, No. 10, No. 14 And the frequency of the band 18 is also very high. The No. 2 strip is thicker in each lane, which means that the microbes represented by this strip are dominant microorganisms in the sediment of the North River.

Using the results of the strip comparison, a matrix of the similarity of each sample can be calculated from the Dyes coefficient Cs, as shown in Figure 11: the maximum similarity is $82 \%$ (No. 1 and No. 4), and the minimum similarity is $49.6 \%$ (4 and 5). By comparing the results of the pairwise comparison, there are 7 groups with similarity exceeding $60 \%$, and the flora structure between them is similar.

$\begin{array}{crrrrr}\text { Lane } & 1 & 2 & 3 & 4 & 5 \\ 1 & 00.0 & 64.0 & 66.7 & 82.0 & 50.8 \\ 2 & 64.0 & 100.0 & 65.0 & 72.2 & 64.6 \\ 3 & 66.7 & 65.0 & 100.0 & 65.5 & 53.2 \\ 4 & 82.0 & 72.2 & 65.5 & 100.0 & 49.6 \\ 5 & 50.8 & 64.6 & 53.2 & 49.6 & 100.0\end{array}$

Figure 11. The similarity matrix of five samples of North River

The variation of the DGGE band number, the Shannon-Wiener index, the Simpson index and the Pielou index of the five sediment samples of The North River is shown in Figure 12. With the increase of DGGE bands, the Shannon-Wiener index and the Pielou index also increased, while the Simpson index decreased accordingly. It can be seen that 
with the increase of bacterial species, population diversity and uniformity increase, correspondingly The advantage is reduced. The maximum value of the Shannon-Wiener index appears in the Chunting Bridge in Section 3, and the minimum appears in the Zhiyuan Bridge in Section 4; the maximum value of the Simpson Index appears in the Chunting Bridge in Section 3, and the minimum appears in the Zhiyuan Bridge in Section 4; the Pielou Index The maximum value appears in the Zhiyuan Bridge in Section No.4, and the minimum value appears in the Chunting Bridge in Section No.3.

From the above analysis, the microbial diversity of the different locations of The North River is rich, with up to 23 bands appearing in a single lane. From the similarity matrix, the similarity of samples at different locations and times is high, the highest similarity is $82 \%$, and the similarity is higher than $60 \%$. Therefore, the North River has a rich microbial population, but its microbial community structure does not change much in space.
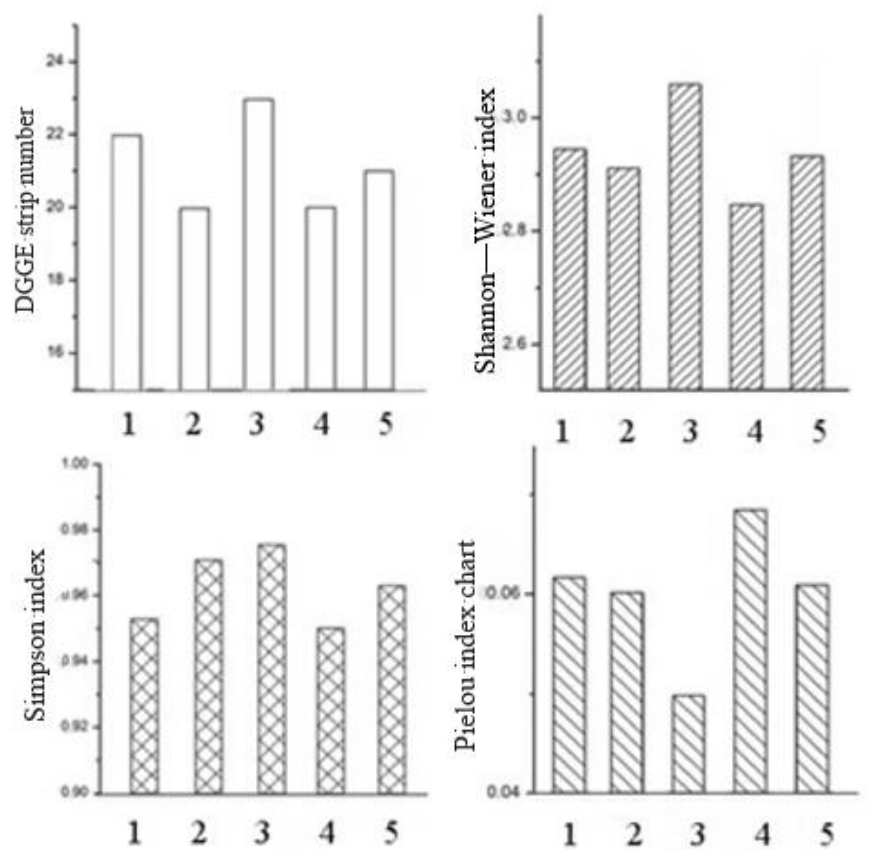

Figure 12. DGGE number of bands, Shannon-Wiener exponents, Simpson exponents and Pielou exponents

\section{Conclusion}

By comparing two methods of microbial DNA extraction from the sediments of the Beihe River (soil DNA mini-kit method and soil total DNA kit combined with humic acid), the latter can be compared with the former for the sediment samples of the Beihe River. The effect of DNA extraction is good. Although the total DNA purity and content of the sediment sample extracted by the total DNA kit and the humic acid method are high, the purity is still affected by protein, phenol and humus, so it is necessary to extract the total DNA of the environmental sample. Need to pay attention to reduce the pollution of proteins, humus, phenol and other substances.

(2) By analyzing the denaturing gradient gel electrophoresis pattern of the sample DNA, it can be seen that the microbial diversity of different locations in the Beishi River is rich, and at most, 23 bands appear in a single lane. From the similarity matrix, 
the similarity of samples at different locations and times is high, the highest similarity is $82 \%$, and the similarity is higher than $60 \%$. Therefore, the micro-population of the Beishi River is abundant, but its microbial community structure does not change much in space.

(3) Based on the analysis and research on the microbial community structure diversity of Beizhou River in Changzhou, it will provide corresponding help for optimizing community structure, regulating community function and discovering new important microbial functional groups, and then cultivate specific dominant functional groups. Future studies concerning the treatment of polluted rivers by microorganisms and related research on water body repair in desperately needed.

Acknowledgements. This study was supported by National Science and Technology Support Program Project (No.2015BAC02B02-01), Changzhou Science and Technology Support Program (Social Development) (CE20175060).

\section{REFERENCES}

[1] Amann, R. I., Ludwig, W., Schleifer, K. H. (1995): Phylogenetic identification and in situ detection of individual microbial cells without cultivation. - Microbiological Reviews 59: 143-169.

[2] Bai, Q. (1997): Chemical valuation method of soil microbial community structure. Agro-Environmental Protection 16(6): 252-256.

[3] Gu, Y., Li, M., Chen, S. (2013): Research progress on urban river eco-logical restoration technology. - Environmental Science and Management 38(4): 25-29.

[4] Handelsman, J. (2004): Metagenomics: application of genomics to uncultured microorganisms. - Microbiology and Molecular Biology Reviews (MMBR) 68(4): 669685.

[5] Hill, J. E., Seipp, R. P., Betts, M., Hawkins, L., Kessel, A. G. V., Crosby, W. L. et al. (2002): Extensive profiling of a complex microbial community by high-throughput sequencing. - Applied and Environmental Microbiology 68(6): 3055-3066.

[6] Hoefel, D., Monis, P. T., Grooby, W. L., Andrews, S., Saint, C. P. (2005): Profiling bacterial survival through a water treatment process and subsequent distribution system. Journal of Applied Microbiology 99(1): 175-186.

[7] Hu, H., He, M., Zhu, M. (2005): Water purification and ecological restoration technology for polluted rivers and its integration strategy. - Water Supply \& Drainage 31: 1-9.

[8] Ibekwe, A. M., Kennedy, A. C. (1998): Phospholipid fatty acid profiles and carbon utilization patterns for analysis of microbial community structure under field and greenhouse conditions. - FEMS Microbiology Ecology 26(2): 151-163.

[9] Li, Y. H., Xu, Q. G., Zhao, Y., Li, Q., Wei, Z. M., Zhao, X. Y. (2013): Bacterial community structure in different spatial distribution of Songhua Lake. - Journal of AgroEnvironment Science 32(4): 764-770.

[10] Liu, Y. J., Liang, Y. T., Qin, W., Xiao, X., Zhao, Y. (2013): An analysis of Beishi River's environmental status and dominant factors. - Journal of Changzhou University 25(2): 2429.

[11] Muyzer, G., de Waal, E. C., Uitterlinden, A. G. (1993): Profiling of complex microbial populations by denaturing gradient gel electrophoresis analysis of polymerase chain reaction-amplified genes coding for $16 \mathrm{~S}$ rRNA. - Applied and Environmental Microbiology 59(3): 695-700.

[12] Pace, N. R. (1997): A molecular view of microbial diversity and the biosphere. - Science 276: 734-740. 
[13] Peng, D., Liu, L., Hu, J. (2009): Vertical distribution and bio-availability of various forms of phosphorus in the sediments of Xuanwu Lake. - Water Resources Protection 25(1): 31-35.

[14] Qin, W., Liu, Y., Zhao, Y. (2014): Evaluation of N and P in sediments of The North River and their effects on microbial population. - Journal of Changzhou University 26(1): 74-79.

[15] Röttgers, R. (2007): Comparison of different variable chlorophyll a fluorescence techniques to determine photosynthetic parameters of natural phytoplankton. - Deep-Sea Research Part I: Oceanographic Research Papers. DOI: 10.1016/j.dsr.2006.12.007.

[16] Sun, D. (2015): Advances in research on urban river ecological health assessment and environmental pollution remediation technology. - Environmental Protection and Circular Economy 1: 49-51.

[17] Sun, J., Liu, D. (2004): The application of diversity indices in marine phytoplankton studies. - Acta Oceanologica Sinica 26(1): 62-75.

[18] Torsvik, V., Goksoyr, J., Daae, F. L. (1990): High diversity in DNA of soil bacteria. Applied and Environmental Microbiology 56: 782-787.

[19] Tunlid, A. (2007): Molecular biology: a linkage between microbial ecology, general ecology and organismal biology. - Oikos 1999(85): 177-189.

[20] Victorio, L., Gilbride, K. A., Allen, D. G., Liss, S. N. (1996): Phenotypic fingerprinting of microbial communities in wastewater treatment systems. - Water Research 30(5): 1077-1086.

[21] Xu, Q., Zhang, F., Xu, Z. (2011): Some characteristics of Simpson index and the Shannon-Wiener index and their dilution effect. - Pratacultural Science 28(4): 527-531.

[22] Yan, S., Wang, X. (1999): Preliminary study on the roles and applied ways of urban river in urban ecological construction. - Urban Environment \& Urban Ecology 12(6): 36-38.

[23] Yu, J., Feng, X., Xie, Y. H., Liu, S. C. (2010): PCR-DGGE and its application in the research of environmental microbiology. - Journal of Northwest A \& F University (Natural Science Edition) 38(6): 227-234.

[24] Zeng, J., Yang, L., Li, J., Liang, Y., Xiao, L., Jiang, L., Zhao, D. (2009): Vertical distribution of bacterial community structure in the sediments of two eutrophic lakes revealed by denaturing gradient gel electrophoresis (DGGE) and multivariate analysis techniques. - World Journal of Microbiology and Biotechnology 25(2): 225-233.

[25] Zhang, Z. N., Wu, X. F., Chen, Y. H. (2009): Application in research on microbial diversity of environment by DGGE technique. - Biotechnology Bulletin 12: 48-52.

[26] Zhao, Y. W., Cai, M. Y., Qian, B., Wang, D. S. (1986): A preliminary study on microbial ecology of the river in city. - Acta Microbiologica Sinica 26(3): 200-205.

[27] Zhu, L., Zhang, L., Wang, H. (2011): Comparative study of DNA extraction methods of microorganisms in river sediment. - Chinese Journal of Environmental Engineering 5(4): 935-938. 